\title{
Is short term counselling recommended for sub-clinical mental health difficulties in school going adolescents?
}

\author{
Akoijam Linthoi ${ }^{1}$, Uma Hirisave $^{2}$ \\ ${ }^{1}$ Clinical Psychologist, Dehradun. \\ ${ }^{2}$ Professor, Department of Clinical Psychology, National Institute of Mental Health and Neurosciences (NIMHANS) \\ - INI, Bangalore. \\ E-mail-alinthoi@yahoo.com
}

\begin{abstract}
Background: The World Health Organization model for school mental health states that psychosocial and mental health issues are present in all schools at different levels. Very often it is assumed that the stresses faced by adolescents can be transitional in nature and will pass away with time and hence those adolescents with subclinical problems tend to fall through the net. Short-term psychological interventions have been suggested to alleviate the distress adolescents' face. This study is aimed to examine if short-term counselling has made any difference for adolescents who has subclinical mental health difficulties.

Methods:Twenty six adolescents in the age range 13-16 years who were identified as having subclinical difficulties were randomized to individual counselling for 5 weeksand assessed at post and 6 month followup. Another group of 26 adolescents received one session of group counselling and were assessedat post and 6 month follow-up. They were assessed using various measures such as evaluations included Problem Checklist, Strengths and Difficulties Questionnaire (SDQ) and Pre-adolescent Adjustment Scale.

Results: At baseline, both groups had similar demographics, adjustment difficulties, nature and severity of problem,chronic nature, distress, social impairment and burden for others. Those who received counselling reported significant reduction in the number of problems perceived, difficulties experienced and improvement in adjustment immediately after counselling session and these improvements were maintained at 6 month follow-up while there were no changes reported in any of the domains for those who received only one session of general problem-solving skills.

Conclusions: Counselling is a valuable intervention and must be used regularly in the management of subclinical difficulties in school going adolescents.
\end{abstract}

Key words: Adolescent, subclinical problems, short-term psychological intervention, difficulties and adjustment.

(Paper received $-20^{\text {th }}$ March 2016, Peer review completed $-28^{\text {th }}$ April 2016, Accepted $-8^{\text {th }}$ May 2016)

\section{INTRODUCTION}

It is widely acknowledged that during adolescent growing up, they encounter various stressors some of which are considered part of normal growing up such as physical growth and hormonal changes and that they will outgrow the problems. The high prevalence rate of psychiatric disorder among adolescents has been highlighted by various epidemiological studies carried out both in India as well as other countries [1]. The World Health Organization model for school mental health states that the psychosocial and mental health issues are present in all schools at various levels. Based on the model, they further highlighted that the models of intervention can be carried out targeting each of the levels. Various studies have highlighted the growing recognition that subclinical problem can pose significant mental health difficulties in adolescents [2-3].An ICMR projectconducted in the year 2000 indicated that majority of students reported 
experiencing mild to moderate levels of stress [4]. Early identification of psychosocial problems and targeting them for intervention has been found to be cost effective and stops adolescent's problems to escalate further. Intervention studies targeted for adolescents with subclinical problems have been found effective [5-6].Researchers have compared a group based preventive intervention CBT with a brief individually supportive intervention with 120 adolescents aged 11-15 years and found that CBT was found to be more effective than just the supportive intervention [7].

There has been hardly any preventive intervention carried out for this group of population. This study is aimed to examine if adolescents with reportedly subclinical problems could benefit at all from receiving some form of counseling or if there 'transitory' problems will subside in due course of time. In order to achieve this aim, a randomized control study was carried out to see if any changes occur in adolescents who received counseling immediately after counseling and if the changes have been sustained. The adolescents who had one contact with the researcher in a group format were also assessed post and 6 months after counseling to see if there have been any changes noted on various domains.

\section{METHODOLOGY}

The adolescents went through a two-stage screening which comprised of General Health Questionnaire (GHQ) [8] and semi-structuredinterview schedule. Those adolescents who were identified as having subclinical problems were randomly allocated to either individual counseling or the minimal contact control group. 26 individuals who fell in the counseling group received 5 sessions of counseling which focused on facilitating ventilation, collaborative goal-setting, problem-solving skills, study skills, information and advice based on individualized formulation. Each session lasted for about 45 minutes. The minimal control group $(\mathrm{N}=26)$ received a group session on general problem solving skills, each group comprising of 5-6 adolescents and lasted for about one hour. They were assessed at pre, post (immediately after the counseling) and 6 month follow-up using Problem Checklist (PCL), Strengths and Difficulties Questionnaire (SDQ) and Pre-Adolescent Adjustment Scale (PAAS).

The Problem-Checklist (PCL): is a checklist which comprises of problems reported by students aged 1418 years the various factors that at home, school and self that interfered with their motivation to study or concentration. It measures the number of problems that adolescents perceive interfere in their lives [9].

The Strength and Difficulties Questionnaire (SDQ): devised by Goodman, has subscales of hyperactivity, emotional symptoms, conduct problems, peer relationships, prosocial behaviour and a total score. It also has an impact supplement that asks if the respondent thinks there is a presence of problem and if so, information for the chronicity, distress, social impairment and burden for others. This is applicable for young people ranging from 4-16 years [10].

The Pre Adolescent Adjustment Scale (PAAS): is a 40 item self-report scale with a Yes/No format which measures adjustment in five areas such as Home, School, Peers, teachers and General along with an overall score for Total adjustment [11]. The PAAS has been used in various Indian studies with adolescents $[1,12]$.

\section{STATISTICAL ANALYSIS}

Chi-squares and analyses of variance (ANOVA) were run to determine if there were significant differences at baseline on demographic characteristics like grade, parental education and occupation as well as on all themeasures used such as GHQ, PCL, PAAS and SDQ including the impact supplement of SDQ between the two groups. The outcome evaluation included repeated measures ANOVA and paired t-test. Chisquare was used to evaluate the SDQ-II which measured the duration of the problem, severity of difficulty, negative impact of problem on self and others and interference of problem on various areas like home, friends, learning and leisure, perception of problem and perception of counseling. 


\section{RESULTS}

Results reveal that there was a significant reduction in the number of total problems reported $(p<0.01)$, problems at home, school and self for those who received individual counseling at post assessment which was further reduced after 6 months. With regards to adjustment, there was significant improvement in peer adjustment at post-assessment and follow-up. On SDQ, a reduction in overall difficulties and on the subscales of hyperactivity and conduct symptoms from pre-post to follow-up. Results indicate that there were no difference in any of the domains measured for those who received one-session of counseling at post-assessment and 6 month follow-up assessment [Table 1 and 2].

\section{DISCUSSION}

This study was aimed to test the hypothesis if adolescents who present with subclinical problems do require counseling or if the problems they report are transitory in nature and would subside with time. The sample comprised of 52 adolescents within the age range of 13-14 years, majority studying in ninth grade, from schools catering to middle and upper middle socioeconomic status in India. The problems reported by the adolescents included increased expectation and academic pressure from parents, fighting with siblings, disturbing neighborhood, strict teachers, lack of friends, increased workload in school, inability to plan time, to name a few. The findings on the SDQ reveal 'borderline' range of difficulties and duration ranged between few weeks to 6 months and of moderate difficulty. The adolescents reported being upset about the problems to a great extent and that others also get upset by the presence of these problems. Although the impact of the problems ranged between mild to moderate in their home life and relationship with friends, it had huge impact on their learning. The baselines measure on PAAS revealed school and academic related stressors as being most significant. These findings are substantiated by previous studies [4,13-15].

Repeated measures of ANOVA with post-hoc multiple comparisons were used to see if receiving counseling made any difference immediately after and at 6 month follow-up on the number of problems reported, difficulties experienced and adjustment. The total number of problems as well as specific problems at home, school and self, reduced significantly both at immediate and 6 month follow-up. Adolescents themselves identified that they wanted to discuss problems related to school and themselves. Individual counseling was effective in bringing down the conduct symptoms, the severity of the difficulties, negative impact of problem on self and others. Thus counseling sessions provided a platform for the adolescents to ventilate about their problems that helped in reducing the severity of difficulties. This is supported by studies carried out by Corcoran and Stephenson [16].Improvement wasshown in peer adjustment 6 months after counseling. Maintenance of changes as well as augmentation of gains in certain areas was evident during follow-up between those who received counseling and those who did not. A meta-analytic review [17] supported the durability of child and adolescent psychotherapy outcome at a mean follow-up interval of 5-6 months.

Adolescents who were in control group showed significant reduction in the number of problemsat home like increased pressure, comparison with others and fights with siblings from pre-post. This implies that one session of general problem solving skills perhaps may have been helpful in to minimal extent as there were no changes reported either in decreasing the difficulties or enhancing adjustment at post and 6 month follow-up. In conclusion, short-term counseling was found to be effective and relevant for those who tend to have subclinical problems.

The findings thus suggest that the hypotheses that the subclinical problems faced by adolescents are temporary in nature and would dissipate with time become doubtful. The adolescents with subclinical problems would definitely benefit from counseling in reduction of the presence of perceived problems, difficulties and enhancing adjustment. Various studies have highlighted that the presence of subclinical problems not warranting a psychiatric diagnosis do pose significant mental health problems in adolescents [2-3]. The study has limitations in that use of problem-solving measure as one of the outcome measure would have added strength to the study and significant life events that would have occurred were not assessed during the intervention period. However, the study has many clinical implications in terms of 
Table 1 - The effects of Individual Counseling

\begin{tabular}{|cccccc|}
\hline \multirow{2}{*}{ Measure } & Pre & Post & 6 months & F value & p value \\
\cline { 2 - 6 } & \multicolumn{5}{c|}{ Mean (SD) } \\
\hline \multicolumn{7}{c|}{ PCL } & \\
\hline Home & $6.88(2.42)$ & $4.38(3.24)$ & $4.54(3.67)$ & 5.99 & $0.005^{*}$ \\
\hline School & $8.88(3.7)$ & $7.54(4.85)$ & $5.12(3.97)$ & 9.22 & $0.001^{*}$ \\
\hline Self & $6.50(2.45)$ & $4.81(2.92)$ & $3.65(3.06)$ & 13.31 & $0.001^{*}$ \\
\hline Total & $22.65(6.46)$ & $16.73(8.41)$ & $13.31(9.36)$ & 16.72 & $0.001^{*}$ \\
\hline \multicolumn{7}{c}{ SDQ-S } \\
\hline Prosocial & $7.04(1.75)$ & $7.38(1.83)$ & $6.62(1.90)$ & 1.827 & $0.17 \mathrm{NS}$ \\
\hline Hyperactivity & $5.15(2.17)$ & $4.50(2.47)$ & $4.0(1.83)$ & 3.550 & $0.036^{*}$ \\
\hline Emotional & $5.54(2.83)$ & $4.54(2.30)$ & $4.46(2.67)$ & 2.550 & $0.088 \mathrm{NS}$ \\
\hline Conduct & $3.69(1.93)$ & $2.65(1.62)$ & $2.42(1.17)$ & 6.740 & $0.003^{*}$ \\
\hline Peer & $4.04(2.41)$ & $3.27(1.40)$ & $3.04(1.84)$ & 2.338 & $0.107 \mathrm{NS}$ \\
\hline Total & $8.35(7.38)$ & $14.96(5.79)$ & $13.92(4.71)$ & 6.39 & $0.003^{*}$ \\
\hline \multicolumn{7}{c}{ PAAS } & & \\
\hline Home & $3.46(5.20)$ & $4.00(4.69)$ & $4.12(5.51)$ & 0.376 & $0.688 \mathrm{NS}$ \\
\hline School & $0.77(3.34)$ & $1.81(2.88)$ & $1.42(3.7)$ & 1.04 & $0.361 \mathrm{NS}$ \\
\hline Peer & $2.96(3.22)$ & $3.85(2.71)$ & $4.23(1.97)$ & 3.34 & $0.043 \mathrm{NS}$ \\
\hline Teacher & $-1.19(4.29)$ & $-1.58(4.22)$ & $-0.96(4.02)$ & 0.215 & $0.807 \mathrm{NS}$ \\
\hline General & $-1.31(2.77)$ & $-0.23(3.48)$ & $0.23(2.64)$ & 2.551 & $0.088 \mathrm{NS}$ \\
\hline Total & $4.73(12.2)$ & $7.77(11.03)$ & $8.50(12.12)$ & 1.514 & $0.230 \mathrm{NS}$ \\
\hline
\end{tabular}

Higher scores indicate higher number of problems, Higher score indicate better prosocial behaviour,

Higher scores indicate higher difficulties, Higher scores indicate better adjustment.

Table 2 - Minimal Contact Control Group

\begin{tabular}{|cccccc|}
\hline \multirow{2}{*}{ Measure } & Pre & Post & 6 months & F value & p value \\
\cline { 2 - 6 } & \multicolumn{7}{c|}{ Mean (SD) } \\
\hline Home & $7.81(3.52)$ & $6.81(3.57)$ & $5.92(3.51)$ & 3.148 & $0.52 \mathrm{NS}$ \\
\hline School & $9.38(4.43)$ & $8.58(3.28)$ & $8.69(3.38)$ & 0.581 & $0.563 \mathrm{NS}$ \\
\hline Self & $6.08(2.38)$ & $5.92(2.24)$ & $6.27(3.09)$ & 0.151 & $0.860 \mathrm{NS}$ \\
\hline Total & $23.31(9.09)$ & $23.31(7.99)$ & $21.31(8.15)$ & 0.838 & $0.438 \mathrm{NS}$ \\
\hline \multicolumn{7}{c}{ SDQ-S } \\
\hline Prosocial & $6.81(1.81)$ & $6.35(1.62)$ & $6.65(1.87)$ & 0.653 & $0.534 \mathrm{NS}$ \\
\hline Hyperactivity & $5.69(2.07)$ & $5.15(1.71)$ & $4.77(1.98)$ & 2.99 & $0.059 \mathrm{NS}$ \\
\hline Emotional & $5.77(2.7)$ & $5.38(2.06)$ & $5.38(2.37)$ & 0.466 & $0.630 \mathrm{NS}$ \\
\hline Conduct & $3.88(2.53)$ & $3.87(1.5)$ & $3.65(1.85)$ & 0.205 & $0.815 \mathrm{NS}$ \\
\hline Peer & $4.19(2.19)$ & $4.31(1.99)$ & $4.15(1.8)$ & 0.055 & $0.946 \mathrm{NS}$ \\
\hline Total & $19.5(6.09)$ & $18.73(4.01)$ & $18.01(5.43)$ & 1.035 & $0.363 \mathrm{NS}$ \\
\hline \multicolumn{7}{c}{ PAAS } & & \\
\hline Home & $1.92(5.38)$ & $3.23(5.26)$ & $3.0(5.25)$ & 1.52 & $0.229 \mathrm{NS}$ \\
\hline School & $-0.04(3.32)$ & $-0.19(3.47)$ & $0.15(2.92)$ & 0.139 & $0.870 \mathrm{NS}$ \\
\hline Peer & $2.19(3.33)$ & $2.12(3.76)$ & $1.73(4.19)$ & 0.202 & $0.817 \mathrm{NS}$ \\
\hline Teacher & $-1.54(4.62)$ & $-2.08(4.13)$ & $-2.77(3.77)$ & 0.966 & $0.388 \mathrm{NS}$ \\
\hline General & $-0.52(2.93)$ & $-0.80(3.0)$ & $-0.60(2.71)$ & 0.114 & $0.892 \mathrm{NS}$ \\
\hline
\end{tabular}

Higher scores indicate higher number of problems, Higher score indicate better prosocial behaviour,

Higher scores indicate higher difficulties, Higher scores indicate better adjustment. 
paying attention to adolescents who may not appear to have a psychiatric diagnosis but do have impairment due to the subclinical problems and highlights the importance of preventive interventions in Indian school setting.

\title{
REFERENCES
}

1. Rozario J. An epidemiological survey of prevalence and patterm of psychological disturbances of schoolgoing early adolescents. Unpublished M Phil Dissertation, Bangalore University ;1988.

2. Pine DS, Cohen E, Cohen P, Brook J. Adolescent depressive symptoms as predicors of adult depression: Moodiness or mood disorders? Am J Psychiatry 1999;156: 133-5.

3. Brent DA, Birmaher B, Kolko D, Baugher M, BridgeJ. Subsyndromal depression in adolescents after a brief psychotherapy trial: Course and outcome. J Affect Disord 2001; 63:51-8.

4. Indian Council of Medical Research. J Ment Health Pract and Advoc 2001; 2:17-18

5. Ginsburg GS, Drake MS. School-based treatment for anxious African-American adolescents: A controlled pilot study. J Am Acad Child Adolesc Psychiatry 2002;41:768-75.

6. Vonk ME, Thyer BA. Evaluating the effectiveness of short-term treatment at a university counseling centre. J ClinPsychol 1999;55:1095-1106.

7. McCarty CA., Violette HD. Duong MT, Cruz RA., McCauley E. A Randomized Trial of the Positive Thoughts and ActionProgram for Depression among Early Adolescents.J Clin Child AdolescPsychol 2013; 42(4):554-63.

8. Goldberg, D. \&Williams,P. A user's guide to the General Health Questionnaire. Berkshire: NFER Nelson (1988).

9. Hirisave U. Problem Checklist ; 1999. (Personal Communication)

10. Goodman R. The Strengths and Difficulties questionnaire: A research note. J Child Psychol Psychiatry 1997;40:791-801.

11. Pareek U, Rao TV, Ramalingswamy P, Sharma BR. Manual for the battery of preadolescent personality tests. Rupa Psychological Corporation, Varanasi; 1975.

12. Bhola P. Supportive psychotherspy with emotionally disturbed adolescent girls in schools. Unpublished $\mathrm{Ph}$ D thesis, NIMHANS, Deemed University, Bangalore ; 2000.

13. Rangaswamy K. Academic stress and mental health . Indian J ClinPsychol 1995;22:1-2.

14. Gibson-Cline J. Adolescence:From crisis to coping. Oxford: Butterworth-Heinman ; 1996.

15. Sinha UK. Supportive psychotherapy with emotionally disturbed adolescent boys in school setting. Unpublished Ph. D thesis, NIMHANS, Deemed University, Bangalore ; 1997.

16. Corcoran J, Stepehnson M. The effectiveness of solution-focused therapy with child behavior problems: A preliminary report. Fam Society 2000;468-74.

17. Weisz JR, Weiss B, Han SS, Granger DA, Morton T. Effectiveness of psychotherapy with children and adolescents revisited: A meta-analysis of treatment outcome studies. Psychol Bull,1995;117(3): 445-68.

\author{
Acknowledgements - Nil \\ Source of Funding - Nil \\ Conflict of Interest - Nil
}

